\title{
THE PATHOLOGY OF GONORRHEA
}

\author{
BY \\ A. H. HARKNESS
}

Hon. Medical Officer in Charge of Venereal Diseases Department, St. Peter's Hospital; Consultant in Venereal Diseases to the London County Council; Consultant in Venereal Diseases to the Royal Navy

Progress in the study of the pathology of gonorrhœa became possible only after the discovery of the gonococcus in 1879 by Neisser. The introduction of the Gram stain in 1884, the cultivation of the gonococcus by Leistikow in 1882 and by Bumm in 1885 , and the fermentation tests for the differentiation of the various Neisseriæ - devised by Elser and Huntoon in 1909-led to greater accuracy in the elucidation of gonorrhœal processes.

Much of the work has been carried out on the cadavers of patients who, suffering from gonorrhœea, have died from inter-current disease.* Baraban had the opportunity. of investigating gonorrhœal processes in a subject who had died by hanging, and Rost made similar observations in the case of a suicide. The disease has been transmitted by inoculation of the urethra in moribund patients (Bockhart, 1883 ; Finger and others, 1894) and of the eyes of blind and normal individuals (Krause, 1882; Bumm, 1884). In this connexion it is interesting to note that Piringer, thirty-eight years before the discovery of the gonococcus, inoculated the eyes of blind people with what was presumed to be gonorrhœal pus and afterwards remunerated the victims. Studies have been made of diseased organs, chiefly of the female, removed at operation (Wertheim, 1890 ; Bumm, 1897 ; Madlener, 1895 ; Velhagen, 1937), and Councilman (1893) has reported on the organs of subjects dying from such gonorrhœal complications as pericarditis and polyarthritis. Similarly, post-mortem investigations have been made in patients dying of gonorrhœal endocarditis (Frisch, 1891 ; Finger and others, 1894) and meningitis (Bieck, 1907; Smith, 1922). Rotky has described the post-mortem findings in gonorrhœal pyæmia with polyarthritis. Material for biopsy also has been excised from infected sites such as the para-urethral and preputial ducts (Touton, 1889 ; Jadassohn, 1890 ; Cohn, 1907 ;

* See the writings of Bumm (1884), Horner (1889), Wertheim (1890), Dinkler (1894), Finger (1891; 1893), Hartmann (1895), Schridde (1905), Byers (1907), Rost (1910), Jacoby (1924), and Santalow and Nowotelenowa (1936).
Pick, 1889), the dorsal lymphatics of the penis (Scholtz, 1899 ; Nobl, 1901), and ano-rectal lesions (Frisch, 1891 ; Hartmann, 1895 ; Harkness, 1948). Samek has performed biopsies on the inguinal glands, and other observers have similarly investigated the cervical and vaginal mucosa (Wertheim, 1890 ; Bumm, 1897) and the male and female urethra (Bumm, 1897 ; Lohnstein, 1906 ; Jacoby, 1924). Biopsy has been carried out on gonorrhœal lesions of the eyes by Waldstein, and lesions of the mouth have been investigated by Rosinski.

Primary infection commonly occurs in the columnar epithelium of the urethra and paraurethral ducts and glands of both sexes, of the cervix, the conjunctiva, of Bartholin's ducts, and of the rectum. A few cases have also been reported in which the portal of entry may have been the pseudo-stratified ciliated columnar epithelium of the nose, but in most of these cases the disease has been secondary to primary infection of the conjunctiva.

Primary infection may also occur in the soft stratified squamous epithelium of the vagina in little girls, and penetration of this type of epithelium in other parts of the body such as the skin, cornea, mouth, para-urethral and preputial ducts is also considered by some workers to take place; but infection of these structures is admitted by all to be extremely rare.

\section{The Penetration of Columnar Epithelium by Gonococci}

Primary Infection of the Male Urethra.-The female urethra often escapes infection, owing no doubt to the fact that it is lined almost entirely by stratified squamous epithelium with only a few scattered areas of columnar epithelium. The male urethra on the other hand, with its stratified or pseudo-stratified columnar epithelium, beginning at the neck of the fossa navicularis and extending backwards as far as the utriculus masculinus in the prostatic urethra, is a more favourable soil for penetration by the gonococcus. 
Gonococci have never been seen in the stratified squamous epithelium of the fossa navicularis of the male urethra, and even though man has no natural immunity to the disease this structure is a barrier to infection. It is true that the gonococcus does get beyond this barrier to reach the susceptible columnar epithelium, but many men escape infection in spite of the fact that their sexual partners are harbouring large numbers of organisms. When this barrier is lacking, as it is in all cases of hypospadias when the distal end of the urethra is lined with columnar epithelium, infection is almost certain. I make a note of this anatomical deformity in all cases of urethritis, gonococcal and nongonococcal, and find that its incidence in patients suffering from urethritis is 1 in 25 , whereas Rennes and de Buisson (1922) report the incidence of hypospadias to be 1 in 300 . . I must add, however, that the commonest type of hypospadias, which has not previously been described, is intrameatal in position and can be detected only by everting the lips of the external urinary meatus. It would have been extremely interesting if Mahoney and his collaborators (1946), who precluded from their study all cases with anatomical abnormality, had included a group afflicted by hypospadias in their experimental inoculations of gonorrhœa in human volunteers.

Gonococci possibly grow on the surface but do not penetrate the epithelium of the fossa navicularis, and a real foothold is gained only when they reach the susceptible stratified or pseudo-stratified columnar epithelium. Penetration takes place through the intercellular.spaces, and organisms have been observed to reach the subepithelial connective tissue on the third (Finger and others, 1891) and fourth (Jacoby, 1924) day. The capillaries are dilated, and there is an exudation of cells and serum. Dense cellular infiltrations consisting of polymorphonuclear leucocytes with a small number of lymphocytes, plasma, and mast cells soon make their appearance beneath the columnar epithelium, being particularly numerous in the region of Littré's glands and ducts. The inflammatory reaction involves the deep tissue of the corpus spongiosum and may extend into the corpora cavernosa.

Involvement of the epithelium is patchy, with intervening areas of normal epithelium. In the diseased parts the intercellular spaces are much widened and contain large numbers of leucocytes, and the epithelial cells are disorganized and much desquamated, with small local areas in which they have completely disappeared, with exposure of the subepithelial connective tissue. Large numbers of polymorphonuclear leucocytes, many. of them containing gonococci, find their way from the acutely inflamed area in the subepithelial connective tissue into the lumen of the urethra. These, together with the serum and the desquamated epithelium, form the profuse yellow-and sometimes sanguineous-discharge which is characteristic of the disease.

The lacunæ of Morgaǵni, being simply invaginations of the urethral mucous membrane, show the same changes as those already described. Similar changes are observed in the ducts of Littrés glands, which may become obstructed by leucocytes and desquamated epithelial cells. In contrast, gonococcal invasion of the secretory cells of the glands, although noted by Rost (1910), has rarely been reported by other workers ; indeed certain observers (Finger and others, 1894; Buschke and Langer, 1926) maintain that they always remain free from organisms. Obstruction of the ducts results in the formation of retention cysts or abscesses. There is invariably an associated periglandular inflammation, and a combination of the two conditions may lead to small indurations around the urethra which may coalesce to form large peri-urethral indurations or abscesses. Spontaneous rupture of a peri-urethral abscess may be followed by a fistula, which rarely persists in the absence of a stricture and, in my experience, only when situated on the floor of the fossa navicularis.

Knowledge of the pathology of gonorrhoea shows the futility of many of the methods of treatment in common use before the introduction of drugs which attack the infection through the blood stream. Local treatment with strong chemicals and excessive instrumentation injured a mucous membrane already damaged and never reached the infection which was always present in the subepithelial connective tissue.

When the acuteness of the infection is subsiding there is reconstruction of the lost or injured areas of mucous membrane and the submucous exudate becomes absorbed. A single layer of flat cells appears over the granulating surface of the denuded areas or on the surface of the damaged columnar epithelium. The process continues until there are seven or eight layers of stratified squamous epithelium which may compress and destroy any underlying columnar epithelium. Before the advent of specific remedies the first attack of gonorrhœa was usually prolonged and severe, whereas subsequent infections reacted much more rapidly to routine or even abortive treatment ; this doubtless was due to the replacement of columnar epithelium by many areas of squamous epithelium.

These localized areas of stratified squamous or pavement epithelium with residual infection beneath them are the so-called areas of "soft infiltration." 
Urethroscopy carried out during the acute phase of the disease will reveal them as reddish tumours which bleed on the least pressure and bulge into the cannula. In the subacute or chronic phase, howèver, which we are now considering, they are seenchiefly on the roof and lateral walls of the urethraas pale pearly grey and gelatinous-looking tumours of varied size which project into the urethral canal and appear to arise from the subepithelial connective tissue. In the subepithelial connective tissue of these areas polymorphonuclear leucocytes are replaced by small round cells transformed in turn to fibroblasts, with the result that these areas of the urethra gradually become surrounded by a thin layer of fibrous tissue. This process, which begins immediately under the epithelium and gradually spreads more deeply, is called "hard infiltration." The persistence of infection leads to sclerosis of this fibrous tissue until the whole thickness of the erectile tissue becomes transformed into a fibrous mass and a true stricture develops. I have on more than one occasion (once with Swift Joly) observed by urethroscopy the change from soft infiltration to hard infiltration or stricture. In the early stages the contracting fibrous tissue raises the mucous membrane of the areas involved, and air-distension urethroscopy demonstrates multiple white glistening and sickle-shaped projections with sharp edges. These are the so-called " crescents" which occasionally occupy the whole circumference of the urethral canal and give rise to an annular stricture of wide calibre. "Crescents," in my experience, may follow both the submucous infiltrations of gonorrhœa and the superficial "epithelial" infiltrations of Waelsch urethritis. In the latter the condition remains stationary but in the former the submucous tissue between the crescents later becomes infiltrated with fibrous tissue, leading to contraction of the urethra.

\section{The Mode of Spread after Primary Invasion}

I have endeavoured to trace the perpendicular spread of infection through the intercellular spaces of the columnar epithelium to the subepithelial connective tissue after primary inoculation, and shall now pass to the local spread of the diseasehorizontal spread - and the method by which gonococci reach remote parts of the body. Bumm and Bockhart both state that gonococci, after penetrating the intercellular spaces of the columnar epithelium, may pass not only into the subepithelial connective tissue but also directly into the lymphatic vessels. In Bockhart's case the lymphatic vessels of the fossa navicularis were almost choked with organisms. Direct invasion of a blood vessel was observed by
Wertheim in one of his cases. The work of others, and my own observations, suggest that the extension of infection backwards to the posterior urethra rarely occurs by the slow route of epithelial continuity. Barrington and Wright (1930) have shown that bacteriæmia may develop within two to seven minutes of urethral injury in patients with infected urine ; and Walker (1913) found organisms in the seminal vesicles, prostate, and epididymis of guineapigs killed ten hours after a loopful of organisms had been deposited in the urethra ; organisms were also found in the lymphatic vessels. Again, I have soen patients suffering from acute gonorrhoa in whom acute local complications, such as prostatitis and epididymitis, or metastatic complications such as arthritis, have developed during the first twentyfour hours of the disease as a result of urethral trauma. Therefore it is reasonable to suppose that spread of infection takes place from the subepithelial connective tissue. However, it must be emphasized that gonococci on reaching the subepithelial tissue of the urethra or rectum may pass upwards or downwards, as I have often detected them beneath the skin of the anus or anal canal after they had penetrated the rectal mucosa ; many observers also have noted organisms beneath the squamous epithelium of the fosşa navicularis after they had penetrated the columnar epithelium.

Pathological Changes in the Posterior Urethra.Changes in the subepithelial connective tissue of the posterior urethra are similar to those already described in the anterior urethra after primary inoculation. Dense cellular infiltrations are particularly numerous in the region of capillaries and prostatic ducts, the latter being filled with desquamated epithelium and polymorphonuclear leu. cocytes. Desquamation is often seen in the superficial layers of the transitional epithelium, but it is well marked only in the columnar epithelium of the -openings of the prostatic and ejaculatory ducts, in which regions replacement by squamous epithelium may be seen.

Local Complications in the Male.-Inflammations of Littré's glands, soft infiltrations, peri-urethral indurations, and abscesses have already been considered. Infection of the para-urethral ducts lined with columnar epithelium produces changes similar to those seen in the urethra.

The disease may reach both the diaphragmatic and bulbar portions of the glands of Cowper, either by way of the columnar-lined duct which opens on the floor of the bulb or by the more rapid lymphatic route. Inflammation, often subacute throughout, may progress to abscess formation. A diaphragmatic abscess rarely remains localized between the 
two layers of the urogenital diaphragm, the pus tracking either downwards to present as a perineal, ischio-rectal, or peri-anal abscess, or upwards to form a peri-rectal or peri-prostatic abscess. Chronically inflamed Cowper's glands are hard and of a brick-like consistency, varying in size from that of a pea to that of a hazel nut. Glands in this condition were excised from two of my patients by Thomson Walker and by Swift Joly; they showed a well-marked peri-glandular inflammation, but the glandular tissue itself was normal (Harkness, 1937).

Acute inflammation of the prostatic ducts and gland with peri-glandular inflammation may cause swelling of one or both lateral lobes-acute prostatitis-which may progress to suppuration constituting a prostatic abscess, the differential diagnosis of the two conditions often being extremely difficult. In chronic inflammation there may be a generalized firmness of the gland, or one lobe may be hard or boggy and the other elastic: alternatively there may be nodular or boggy areas in both lobes.

Infection may also spread by continuity in the columnar epithelium of the short ejaculatory ducts or by the lymphatic vessels to one or both of the vesiculæ seminales. Infection of these glands produces the same histological appearances as those already described in the columnar epithelium of the urethra. In my experience acute involvement of these glands-extremely rare even in the pre-sulphonamide era-is invariably associated with profound constitutional disturbance.

Involvement of the epididymis, the most frequent complication before the introduction of the sulphonamides and penicillin, usually follows trauma of the posterior urethra. In a small proportion of cases the infection unmistakably reaches the epididymis by a slowly descending inflammation in the columnar epithelium and subepithelial connective tissue of the vas deferens. On most occasions, however, the lower pole of the epididymis suddenly shows signs of inflammation before it is possible to detect any abnormality in the vas, and in such cases the mode of spread is either by the lymphatic or blood stream, or conveyed by a few drops of contaminated urine forced down the vas. Gonococci penetrate the columnar epithelium of the tubules of the epididymis in the manner already described, and the only distinctive feature is the formation of multiple miliary abscesses in the subepithelial connective tissue which rarely coalesce to form extensive abscesses. This has occurred in only four of my cases, and in all of them gonococci were present in the evacuated pus. There is often an associated inflammation of the rete testis and an inflammatory hydrocele. An indurated lower pole, due to scarring and obliteration of the canal of the epididymis, usually persists after cure, and bilateral involvement causes azoospermia in a large majority of cases.

The dorsal lymphatics of the penis may become indolently thickened, the condition being associated with œdema of the prepuce and skin of the penis. Gonococci have been found in the endothelium and subepithelial tissue of the lymphatics (Nobl, 1901) and in the small lymphatic gland occasionally found on the dorsum of the penis (Scholtz, 1899). Slightly enlarged and painful inguinal glands are often observed during the acute phase of the disease, but they seldom go on to suppuration. Samek described a case in which there was persistent inflammation of the dorsal lymphatics of the penis with enlarged glands in both groins : gonococci were found in an excised gland. I have had one similar case, and others have been reported by Colomboni (1898), Hocheisen (1906), and Lloyd (1948).

The Penetration of Squamous Epithelium

Vulvo-vaginitis.-Primary involvement of the stratified squamous epithelium of the vagina occurs in little girls. At birth the vaginal epithelium consists of many layers of cells. Fromo the time when the estrin derived from the mother disappears from the circulation until puberty the number of the layers lessen considerably and the epithelium becomes " rugated and cryptic" (Cruickshank, 1938). During this period there is softening of the protoplasm with widening of the intercellular spaces (Bumm, 1897). Further, in children there is an almost complete absence of fermentable glycogen; hence the secretion is alkaline. Also the surface layer of the epithelium does not become horny until puberty. All these conditions render this type of epithelium susceptible to infection.

It is also possible that infection may start in the glands of a cervical type sometimes found in the fornix, and that it may spread from them to the vagina.

The mode of spread, as in all cases where there is penetration of squamous epithelium, is by continuity of the epithelium. Organisms are found only in the upper layers of the epithelium and have never been seen in the subepithelial connective tissue, and in view of this it may be advantageous in treatment to combine local with parenteral administration of penicillin. Dense cellular infiltrations occur in the subepithelial connective tissue, and from these polymorphonuclear leucocytes and lymphocytes migrate into the epithelium. Bumm (1897) states that nests of these cells may be seen beneath partly desquamated epithelium. Ulcers, are pathological 
curiosities in all gonorrhœeal processes, and those described in the past as occurring on the vaginal walls in these cases were undoubtedly due to the effects of caustic treatment.

Inflammation of the Para-urethral and Preputial Ducts.-The investigation of infected para-urethral and preputial ducts has been carried out by Touton (1889), Jadassohn (1890), Cohn (1907), and Pick (1889). Both squamous and columnar epithelium came under observation in Cohn's case, but only the superficial layers of the squamous epithelium contained gonococci. It is possible that the duct was originally lined solely with columnar epithelium, areas of which had been destroyed and replaced by squamous epithelium. In the cases described by Touton, Jadassohn, and Pick the infections were of long standing, and again the epithelial lining may originally have been columnar although it was squamous at the time of investigation. Gonococci were found only in the superficial layers of cells, and in Touton's case they were not found deeper than the fourth layer.

Stomatitis.-Infection in the stratified squamous epithelium of the mouth is extremely rare. In most of the cases described in the literature whitish yellow patches, surrounded by reddish zones, occurred, chiefly on the soft palate, tonsils, tongue, and gingival margins. In the case described by Frazer and Menton (1931), however, the buccal mucosa, gums, and tongue were covered with an adherent greyish membrane. Pre-existing ulceration of the mouth, noted in the case described by Klepper (1925), may be the determining factor in oral infections. Rosinski described four cases of oral infection in babies, and in two of them he excised biopsy material from the tongue and gum margin. He found that gonococci, always extracellular, had penetrated deeply into the epithelium but had not reached the subepithelial connective tissue.

Infection in the Female.-The vulvo-vaginal infection of female children having been considered, we pass to the gonorrhoal infections of the adult female.

The cervix, urethra, and Bartholin's glands are the usual sites of primary infection in the female and one or more of these structures may be involved at the same time. The rectum, a frequent site of secondary infection in the female, is rarely the primary focus.

Cervical Invasion.-The tall columnar epithelium of the cervix, beginning just within the os externum, but occasionally extending to the outer surface of the portio vaginalis, is the most frequent site of infection. The histological pathology is similar to that of the male urethra. Involvement of the cervical glands, as of Littré's glands, is usually confined to the ducts; but a cystic gland-or Nabothian cyst-excised by Bumm showed gonococcal invasion of the glandular epithelium.

Infection may spread to the uterus and Fallopian tubes by continuity of the epithelium or via the subepithelial connective tissue. Inflammation of the uterus, rarely severe, is usually well marked only in the epithelium and subepithelial connective tissue, but Madlener, in a uterus excised during the tenth week of the disease, also found gonococci deep in the muscular layers.

Salpingitis, usually bilateral, may have an acute onset or the onset may be subacute and mild. In both types there is a tendency for the tubes to become closed and form retort-shaped cavities characterized by a thin wall in the condition known as hydrosalpinx and by a thick wall if pyosalpinx develops. During the acute phase pus may escape from the patent abdominal ostium into the peritoneal cavity and it is even possible that a hydrosalpinx may burst. The result is an acute peritonitis which is usually shut off by adhesions and remains localized to the pelvis. Pus escaping from the fimbriated end may also infect a ruptured Graafian follicle and cause a peri-oöphoritis or interstitial oöphoritis.

Infection of the Urethra.-The female urethra often escapes infection, owing no doubt to the fact that it is lined almost entirely by stratified squamous epithelium with only a few scattered areas of columnar epithelium. Primary infection in all probability occurs either in its columnar epithelium or in the columnar epithelium of Skene's paraurethral glands, which usually open immediately internal to the meatus : but for the presence of these glands, infection would be extremely rare. Infection spreads to other areas lined with columnar epithelium-including the ducts of the urethral glands-and soft submucous infiltrations develop. Peri-urethral indurations or abscesses may occur, but the subsequent formation of urethral stricture is extremely rare, probably because so few areas are involved.

The Glands of Bartholin.-Inflammation, commonly unilateral, is usually confined to the ducts and the periglandular tissues, and I know of no cases recorded in the literature in which gonococcal invasion has been observed in the gland. Bumm agrees with Jadassohn in considering that the secretory function of the gland affords immunity. The infected duct, its orifice often surrounded by a red halo, exudes pus, and owing to its narrowness may become occluded forthwith by the acute 
inflammatory reaction or later by the development of an organic stricture. Infection may result in a small indurated swelling, or a large abscess often preceded by a cystic swelling of the duct or gland.

\section{Rare Complications Affecting both Male and Female}

Cystitis.-Generalized cystitis is extremely rare, but a localized inflammation of the trigone of the bladder may accompany acute posterior urethritis in the male and inflammatory conditions of the short female urethra. This is possibly due to involvement of the Littré-like glands in the invaginations of the epithelium in the region of the internal meatus.

Finger (1891) and Wertheim (1890) state that organisms are present in the desquamated transitional epithelium and in the subepithelial connective tissue; on one occasion Wertheim observed the direct invasion of a blood vessel, as has been mentioned.

Ureteritis, Pyelitis, Pyelonephritis, Pyonephrosis. -These conditions are extremely rare. Including the case described by Worcester and myself in 1937 only fourteen examples of proved gonococcal infection of the kidney have been reported in the literature. There are no true glands in the calyces, renal pelvis, or ureter, and all these structures are lined with transitional epithelium which does not favour the ascent of infection by continuity of surface. Infection is in all probability conveyed by the blood stream, the lymphatics of the ureter, or the back flow of urine from an infected bladder.

Conjunctivitis.-Primary gonorrhœa of the conjunctiva occurs rarely in adults but is common in babies infected during birth, constituting ophthalmia neonatorum.

There is an intense redness and swelling of the conjunctiva associated with a profuse purulent and often blood-stained discharge. The ocular conjunctiva swollen with an inflammatory œdema bulges over the cornea, and for the same reason the upper lid may overlap the lower.

The histological pathology is similar to that already described in the male urethra. Bumm carried out a complete study of the eyes of twentysix children who had died at intervals varying from a few hours to thirty-two days after birth. He observed an intense inflammatory reaction in the subepithelial connective tissue of the conjunctiva during the first twenty-four hours and detected gonococci there on the second day of the disease. There is gross destruction of the, epithelium, and reconstruction has been observed as early as the fifth (Bumm, 1897) and sixth (Waldstein, 1909) day when a single layer of cells appears over the granulating surface of the denuded areas. Bumm states that the newly formed epithelium sometimes proliferates to such a degree that the downward growth gives the impression of a pseudo-epithelioma.

The acute inflammatory reaction of the conjunctiva ends abruptly at the lumbus cornex, and the majority of workers (including Bumm, Horner, and Waldstein) maintain that gonococci do not penetrate the stratified squamous epithelium of the cornea. The only dissentient is Dinkler (1894), who claims to have found gonococci in the superficial squamous layers in an eye excised for panophthalmia. Corneal ulceration is, in my opinion, not due to penetration of the epithelium by the gonococcus but is caused by (1) manipulation, (2) excessive inflammatory œdema of the conjunctiva which strangles the vessels at the limbus cornex, and (3) pressure of pus under the lids which macerates the cornea.

Waldstein carried out biopsies on material from fifteen cases, babies and adults, suffering from gonorrhœal conjunctivitis of two to sixty days standing, and also on material from cases of abacterial conjunctivitis as well as conjunctivitis due to the Micrococcus catarrhalis. It is interesting to note that abacterial conjunctivitis was only distinguishable from the gonococcal variety by the absence of gonococci ; and in conjunctivitis due to the $M$. catarrhalis there was no destruction of epithelium and the organisms were seen only in the superficial layers.

Local Complications of Conjunctivitis. - Complications such as corneal ulcers, keratitis, iritis, abscess of the eyelids, and the more rarely seen cellulitis of the orbit and panophthalmia occurred in the past. These conditions have become extremely rare since the advent of specific therapy, and it may be remarked here that the same is true of rhinitis, pre-auricular adenitis, and meningitis. Infection of the lachrymal gland has not, to my knowledge, been reported in the literature.

A note on the ophthalmic lesions of metastatic origin is added later.

\section{Ano-rectal Gonorrhoea}

Infections of the Rectum.-Ano-rectal gonorrhœa, a much more frequent disease than is generally supposed, may be primary or secondary. Secondary manifestations occur chiefly in women and little girls with a primary genito-urinary infection, and occasionally they result from the bursting of gonorrhœal abscesses into the rectum. Primary infection usually results from sodomy but may be accidental, and in many cases it has followed the insertion of contaminated thermometers or enema 
nozzles. Stühmer (1921) described the occurrence of infection in twenty-six soldiers after prostatic massage with a glove contaminated by gonococcal pus.

I have studied the minute pathology from biopsy material obtained for me by Milligan using a punch. The material was derived from the rectal mucosa, the anal mucosa, and the skin of the anal canal from eleven cases of primary disease in males contracted by sodomy. The sections were stained by Dossett's modification of von Wahl's method (Harkness, 1944), which has been found very successful in demonstrating gonococci.

Sections showed areas of disorganization and degeneration of the columnar mucus-secreting epithelium both on the surface and in the crypts of Lieberkühn, and in some areas it is destroyed entirely, with exposure of the subepithelial connective tissue. In this tissue there is engorgement of the capillaries, which are surrounded by a cuff of polymorphonuclear leucocytes, lymphocytes, plasma cells, and monocytes. Inflammatory cells are too numerous to allow of any evidence of exudate. Gonococci, chiefly extracellular in position, are seen in the necrosed mucous membrane. Intracellular organisms are seen more frequently in the subepithelial connective tissue and are particularly numerous beneath the areas of necrosed mucous membrane. Their number diminishes as one approaches the muscularis mucosæ, and organisms were never seen in or beyond this structure. Metaplasia from columnar to squamous epithelium, already described as occurring in the urethra, cervix, and conjunctiva, was not observed in any of my cases.

The Anal Canal.- No changes were observed and no gonococci were seen in the stratified cuboidal or modified squamous epithelium of the anal canal, although the tissue reaction in the subepithelial connective tissue and the distribution of gonococci, both intracellular and extracellular, was similar to that seen in the rectum.

Previous work on the pathology has been carried out by Frisch (1891), by Hartmann (1895) and by Santalow and Nowotelnowa (1936). Frisch excised fragments of rectal mucosa from one of his cases, and examined the rectum of a woman who died of endocarditis. Hartmann also excised material during life, and examined the rectum of a girl after death from pulmonary tuberculosis. Both observers reported the presence of gonococci in the rectal mucosa and subepithelial connective tissue. Santalow and Nowotelnowa examined the rectum in the cases of three little girls who, suffering from vulvo-vaginitis, died from intercurrent disease.
Inflammatory changes were observed in two cases, but gonococci were not found.

The portal of entry of gonococci is the columnar epithelium of the rectum, and involvement of the subepithelial connective tissue is secondary. My opinion is that the infection never goes higher than the rectum, but I hope to verify this by an examination of biopsy material from the sigmoid flexure of the next case.

Pathological Progress of the Disease.-During the acute phase of the disease there is a general redness of the rectal mucosa, with large localized areas of red infiltration which may be superficially eroded and bleed on the least injury. In the subacute phase these areas are pale and occasionally granular ; and the anal canal-which showed at first no changes -now has patchy areas of redness or more conspicuous infiltrations, either red or pale. These are situated on or between the columns of Morgagni and are especially well-marked at the ano-rectal junction.

Local complications are peri-anal or ischio-rectal indurations or abscesses with or without the later development of a fistula. Condylomata acuminata, due to a concomitant virus infection, occur more often in ano-rectal than in genito-urinary gonorrhœa, and in a recent series of 171 cases of primary disease contracted by sodomy they were observed in forty-three instances. The lesions are usually situated on the skin of the anus or in the anal canal as far as the ano-rectal junction; only once have I seen one on the rectal mucosa. Superficial fissuring may occur in association with condylomata acuminata.

Metastatic Complications. - I have already described how gonococci may pass into the blood stream by way of the lymphatics and blood vessels to settle in remote parts of the body. The septicæmia, rarely pure, is almost invariably associated with inflammation of the joints, muscles, bursæ, tendon sheaths, or periosteum; the iris, conjunctiva, endocardium and pericardium, meninges, nerves, and skin are similarly liable to invasion.

Blood-borne complications commonly arise from primary genito-urinary foci of infection, but they have also been reported during the course of ophthalmia neonatorum, conjunctivitis in adults, vulvo-vaginitis, and ano-rectal, oral, and skin infections. I have never seen arthritis or other blood-borne infections co-existing with acute local complications.

Secondary foci of infection, blood-borne in origin and harbouring gonococci for long periods, may play some part in precipitating certain chronic metastatic complications as gonococci have been 
isolated by Rosenow (1914) and by Forkner (1928) in cases of chronic arthritis from benign nonsuppurating hyperplastic lymph-glands, using the method of puncture.

Gonorrheal Arthritis.-Gonorrhœal inflammation of joints is commonly polyarthritic; it was so in 83.4 per cent. of a recent series of 336 cases, and mono-arthritic arthralgic pains were often noted in other joints. The joints most often involved are the knees, ankles, and small joints of the feet. It may occur at any stage of the disease and has usually an acute onset; a subacute onset is rare. Further joints may become affected during treatment, and it is my experience that these return to normal before the joints that were first attacked.

There are three main types of acute joint affection in gonorrhœa-arthralgia, acute synovitis, and acute arthritis which includes sero-fibrinous arthritis and the purulent form. In arthralgia there is articular pain in one or more joints, but swelling and limitation of movement are absent. In acute synovitis, which is the commonest joint manifestation, there is much pain and considerable swelling, chiefly due to effusion into the joint. There is sometimes redness and œdema of the skin covering the joint, together with profound constitutional disturbance : the capsule and periarthritic tissues are rarely involved. The infective process usually remains confined to the synovial membrane and seldom involves the ends of the bone, so that necrosis of cartilage and osteoporosis of the underlying bone rarely occur. The subsequent development of ankylosis, fibrous or osseous, is extremely rare, and in my experience only follows faulty treatment, such as immobilization of joints during the acute inflammatory phase.

Synovial fluid aspirated during the acute phase may be sero-fibrinous or turbid, when it contains large numbers of polymorphonuclear leucocytes with gonococci both intracellular and extracellular. Cultures for gonococci are successful in less than 20 per cent. of the cases, but only when aspiration takes place during the first three or four days. The synovial membrane shows areas of degenerated epithelium with infiltrations consisting chiefly of polymorphonuclear leucocytes with a few lymphocytes and mast cells. Rotky (1912) described the appearances in a woman aged 40 who died from gonococcal pyæmia with polyarthritis. In several joints the inner surface had the characteristics of young granulation tissue, and similar changes were observed between the layers of fatty tissue in the deeper parts : in several places the synovial membrane was completely destroyed. The connective tissue of the muscles surrounding the joints was swollen by the infiltration of erythrocytes, leucocytes, and plasma cells. Many gonococci were present in the areas where the synovial membrane had been destroyed, and a lesser number in the inner zone.

Subacute or chronic arthritis may be of insidious onset or may follow acute inflammation. In the variety denominated hydrarthrosis the joint is distended with fluid: the knee is most often affected. In synovio-articular arthritis there is a predilection for the small joints of the feet and hands and the peri-arthritic tissues are often involved.

Periostitis.-The os calcis is often affected, especially when $x$-ray examination reveals a subcalcanean spur. In 5.9 per cent. of my series of cases this condition was' noted, accompanied by an inflammation of the plantar fascia. In two of these cases there was a small area of periostitis near the spine of the tibia. I have also observed small tender areas at the lower end of the tibia, fibula, and radius in which $x$-ray examination demonstrated a localized periosteal reaction.

Myositis.-Myositis, especially in the muscles related to the joints affected, often occurs ; on one occasion I noted acute myositis of the right trapezius muscle as the only metastatic complication. An instance of suppurative myositis, in which smears and cultures of the pus evacuated showed the presence of gonococci, was reported in 1904 by Harris and Haskell (1904).

Bursitis.-This was noted in ten of my 336 cases of gonococcal arthritis. The bursa underlying the semimembranosus muscle, the prepatellar and subpatellar bursæ, and the olecranon bursa each provided two examples. The bursa between the tendo Achillis and the os calcis, and the bursa over the gluteus medius muscle, each provided one example. A further case showed involvement of the subpatellar bursa as the only blood-borne complication.

Teno-synovitis.-This may be dry, serous, or suppurative, and the majority of my cases have occurred in the extensor tendons of the wrist. A teno-synovitis affecting the triceps tendon of the right arm was not associated with arthritis. In none of my cases did suppuration occur.

By no means all cases of arthritis-or the other complications enumerated-that arise during an attack of gonorrhœe are necessarily due to the gonococcus. This is now proved by the fact that successful penicillin therapy eliminates gonococci from the primary foci and if the infection is purely gonococcal complications do not ensue. If, however, the infection is composed of gonococci mixed 
with other organisms or a virus, penicillin eliminates the gonococcal element of the urethral discharge but the non-gonococcal element persists. In such circumstances acute inflammation in one or more joints may follow days, weeks, or months later. In none of these cases have I been able to demonstrate gonococci in the urethral discharge and synovial fluid, and in my opinion the arthritis is of nongonococcal causation. The same remarks apply of course to complications following a purely nongonococcal urethritis. In this respect it is interesting to note that pleuropneumonia-like organisms have been isolated by Dienes and his collaborators (1948) in the synovial fluid of two patients with Reiter's syndrome, and by Warthin (1948) in a similar case.

Metastatic Conjunctivitis.-This condition, invariably bilateral, is usually mild and in my experience is always associated with arthritis. Gonococci have never been found in the discharge or in the conjunctiva. The complication is in my opinion due to a concomitant non-gonococcal infection, as I have found inclusion bodies in conjunctival scrapings.

Iritis and Keratitis.-These inflammations, often unilateral, may be the only blood-borne complications and are frequently resistant to treatment. Again, gonococci have never been found in the lesions of man, and both conditions may have a non-gonococcal ætiology.

Both Karnitski (1897) and Sidler-Huguenin (1911) have found gonococci in pus aspirated from the anterior chamber of the eye in patients suffering from gonococcal iritis, and Byers reported the histo-pathological findings in a case of gonorrhœal iritis occurring in a youth who died from intercurrent disease. There was swelling and roundcelled infiltration of the iris, but no gonococci were seen in sections of the iris and ciliary body. Similar findings in an eye excised for panophthalmitis have been reported by Velhagen. On the other hand Drell and his collaborators, as a result of their inoculation experiments on rabbits, reported that " an occasional gonococcus could be distinguished in the iris." This was in addition to a moderate to severe inflammatory reaction in the iris and ciliary body.

Gonorrhoeal Affections of the Skin.-In my experience gonorrhœal ulcers of the skin usually occur locally in association with genito-urinary or rectal foci of infection, but instances have been reported of primary involvement of the skin, both genital and extragenital (Thomson, 1923 ; Pugh,
1930 ; Lowry and Franks, 1943). Ulceration may also be of systemic origin.

Gonococci are unable to penetrate a healthy epidermis, and in my opinion preliminary destruction of at least the superficial layers of the stratified squamous epithelium with possibly exposure of the corium is necessary before organisms are able to gain a foothold. Such destruction is commonly effected by trauma or by intertriginous dermatitis. In most cases penetration of the skin is probably from within, as it is in systemic ulceration ; indeed this may be the pathology of all gonococcal ulcers associated with primary genito-urinary and rectal infection. I have seen ulcers develop after the spontaneous rupture of a single subcutaneous abscess and of multiple small abscesses along the course of a gonococcal lymphangitis or an infected para-urethral duct.

Systemic involvement of the skin occurs during the course of a gonococcal septicæmia and may consist of simple erythema, erythema multiforme, erythema nodosum, purpura, vesiculo-pustular eruptions, and subcutaneous abscesses. Gonococci have been demonstrated in erythematous (Ichikama and Olimori, 1937), purpuric (Paschen and Jentz, 1922), and vesiculo-pustular eruptions (Dorner, 1923 ; Lidström, 1929 ; Harkness, 1945). Krepschmer, cited by Hauck (1935), considers that these metastatic eruptions are due to emboli composed of gonococci arising from other complications such as arthritis.

It will be noted that keratodermia blennorhagica has not been included as a skin manifestation of gonorrhoea as it is probably a blood-borne complication of non-gonococcal urethritis (Harkness, 1945) due either to a virus or to pleuropneumonialike organisms.

Meningitis.-Less than fifty cases of gonococcal meningitis have been recorded in the literature, and in some the bacteriological diagnosis was not complete. The complication may be blood-borne from primary foci in adults and babies, but Branham and her collaborators report the case of a girl aged 16 in whom a primary focus could not be detected. These workers consider that gonococcal meningitis occurs more often than is generally supposed, as ten of five hundred cultures received by them for typing as meningococci were found to be gonococci. In the fatal case described by Bieck, autopsy showed patches of purulent exudate containing gonococci in the subarachnoid space, the exudate being most obvious in the frontal and parietal regions, as is usual in other types of purulent meningitis.

In 1933 I saw, in consultation with F. J. Poynton at University College Hospital, a man aged 37 with a 
urethral discharge of three months duration and meningitis. Gram-negative diplococci were present in the urethral discharge and cerebrospinal fluid, and cultures of the latter yielded a heavy growth of a Gram-negative diplococcus : unfortunately cultures of the urethral discharge were sterile. I was asked whether the patient's condition was due to the gonococcus, meningococcus, or both, and replied that the diagnosis rested entirely with the laboratory. Antimeningococcal serum had no beneficial effects on the meningitis, but improvement and subsequent cure followed urethro-vesical irrigations.

Gonorrhceal Neuritis.-Instances of this condition, usually affecting the sciatic nerve, have also been described ; but absolute proof is lacking and many, if not all, are due to referred pain arising in the infected joints.

Acute Endocarditis.-Inflammation of the endocardium may arise during the course of a gonococcal septicæmia, and in over 90 per cent. of the cases there is an associated polyarthritis. The first case was observed by Ricord in 1838, and since then not more than 150 cases have been reported in the literature. The commonest sites of infection are the aortic and mitral valves, which may have been the seat of previous infection ; but this is not always. so as it is in subacute bacterial endocarditis. Boyd (1947) states that involvement of the right side of the heart alone suggests gonococcal infection. The valvular vegetations, large, soft, and friable, often extend to the mural endocardium and are frequently associated with deep ulceration causing perforation of the cusps and destruction of the chordæ tendineæ. The tissue reaction is one of acute inflammation, and there is a distinct tendency to repair, as is shown by the presence of fibroblasts in the deeper parts of the lesion and by occasional calcification. Lewis states that the signs of repair are few because resistance is slight and the disease runs a short course. Large numbers of gonococci are found on the surface of the vegetations, and in Dwyer's case of a-girl aged twenty-three months they were also present beneath the ulcerated areas. Gonococcal abscesses due to emboli often occur in many parts of the body.

Pericarditis.-The pericardium is far less commonly affected and pericarditis is rarely associated with endocarditis. The disease runs a more benign course and even before the discovery of specific remedies recovery was usual.

Myocarditis.-This condition is characterized by the presence of small abscesses containing gonococci. Myocarditis does not occur alone but only in conjunction with endocarditis or pericarditis.

\section{REFERENCES}

Baraban, L. (1890). Rev. méd. Est., 22, 361.

Barrington, F. J. F., and Wright, H. D. (1930). J. Path. Bact., 33, 871.

Bieck,. D. (1907). Cited by Thomson, D. (1923). "Gonorrhcea." p. 230. London.

Bockhart, M. (1883). Arch. Derm. Syph. Wien, 15, 3.

Boyd, W. (1947). "A Text-Book of Pathology." Fifth Edit. p. 360 . London.

Branham, S. E., Mitchell, R. H., and Brainin, W. (1938). J. Amer. med. Ass., 110, 1804.

Bumm, E. (1884). Arch. Gynaek., 23, 327. (1885). "Der Mikro-Organismus der gonorrhoischen Schleimhaut-Erkrankungen, Gonococcus-Neisser." Wiesbaden.

(1897). In Veit, J. “ Handbuch der Gynäkologie."' pp. 443-458. Wiesbaden.

Buschke A., and Langer, E. (1926). "Lehrbuch der Gonorrhöe." p. 35.

Byers, W. G. M. (1907). Stud. R. Victoria Hosp., Montreal, 2, 107.

Cohn, P. (1907). Dtsch. med. Wschr., 33, 24.

Colomboni, P. (1898). Z Zbl. Bakt., Abt. I., 24, 955.

Councilman, W. T. (1893). Amer, J. med. Sci., 106, 277.

Cruickshank, R. (1938). In "The Clinical and Administrative Aspects of Vulvo-Vaginitis in Children." p. 17. London County Council Publ., No. 3362.

Dienes, L., Ropes, M. W., Smith, W. E., Madoff, S., and Bauer, W. (1948). New Engl. J. Med., 238, 509.

Dinkler, M. (1894). Arch. Derm. Syph. Wien, 26, 195.

Dorner, L. (1923). Dtsch. med. Wschr., 49, 1549.

Drell, M. J., Miller, C. P., Bohnhoff, M. (1947). Arch. Ophthal, Chicago, 38, 22.

Dwyer, H. L. (1920). J. Amer. med. Ass., 75, 1643.

Finger, E. (1891). Arch. Derm. Syph. Wien, 23, 1.

-(1893). Ibid., 25, 27.

Ghon, A., and Schlagenhaufer, F. (1894). Ibid., 28, 277.

Forkner, C. E. (1928). Bull. Johns Hopk. Hosp., 43, 257.

Frazer, A. D., and Menton, J. (1931). Brit. med. J., $1,1020$.

Frisch, F. (1891). Verh. phys.-med. Ges. Würzburg, 25, 167.

Harkness, A. H. (1937). Brit. J. vener. Dis., 13, 119.

-(1945). Ibid., 21, 45.

(1948). Proc. R. Soc. Med., 41, 476.

- and Worcester, R. G. (1937). Lancet, 1, 375.

Harris, N. M., and Haskell, L. W. (1904). Bull. Johns Hopk. Hosp., 15, 395.

Hartmann, H. (1895). Ann. Gynec. Obstet., 43, 77.

Hauck, L. (1935). In Arzt, L., and Zieler, K. "Die Haut-und Geschlechtskrankheiten," 5, 378. Berlin and Vienna.

Hocheisen, P. (1906). Arch. Gynaek., 79, 415.

Horner, F. (1889). In Gerhardt, C. "Handbuch der Kinderkrankheiten, 5, (Pt. 2), 203. Tubingen.

Ichikama, T., and Olimori, S. (1937). Cited by Redewill, F. H. Urol. cutan. Rev., 41, 781.

Jacoby, M. (1924). Verh. dtsch. Ges. Urol., 6, 310.

Jadassohn, J. (1890). Dtsch. med. Wschr., 16, 542 and 569.

Karnitski, A. V. (1897). Voyenno med. J: (med.-spec. pt.), 190, 824.

Klepper, C. (1925). Derm. Wschr., 39, 1440.

Krause, F. (1882). Zbl. prakt. Augenheilk., 6, 134.

Lewin, A. (1928). In Lichtenberg, A. von, Voelcker, F., and Wildbolz, H. " Handbuch der Urologie," 3, 897. Berlin.

Lewis, T. (1946). "Diseases of the Heart," 4th ed., p. 195. London. 
Lidström, F. (1929). Acta derm.-venereol., Stockh., $10,457$.

Lloyd, V. E. (1948). Personal communication.

Lohnstein, H. (1906). 'Mber. Urol., 11, 67.

Lowry, E. C., and Franks, A. G. (1943). Amer. J. Syph., 27, 428.

Madlener, M. (1895). Z Zbl. Gynäk., 19, 1313.

Mahoney, J. F., Van Slyke, C. J., Cutler, J. C., and Blum, H. L. (1946). Amer. J. Syph., 30, 1.

Marvan, H. P., and Wilkinson, W. E. (1938). J. Amer. med. Ass., 110, 800.

Motz, B. (1903). Ann. Mal. Org. gén.-urin., 21, 419.

Neisser, A. (1882). Dtsch. med. Wschr., 8, 279.

Nobl, G. (1901). "Pathologie der blennorrhoischen und venerischen Lymphgefäss-Erkrankungen." Vienna and Leipzig.

Paschen, E., and Jentz, E. (1922). Med. Klinik, 18, 428.

Pick, F. J. (1889). Verh. dtsch. derm. Ges., 1, 258.

Poynton, F. J. (1933). Personal communication.

Pugh, W. S. (1930). Amer. Med., 36, 126.

Rennes and De Buisson (1922). Cited by NovéJusserand, G. In Pousson, A., and Desños, E. "Encyclopédie française d'Urologie," 5, 858. Paris.
Rosenow, E. C. (1914). J. Amer. med. Ass., 63, 903.

Rosinski, B. (1891). Z. Geburtsh. Gynäk., 22, 216 and 359.

Rost, G. (1910). Z. Urol., 4, 321.

Rotky, K. (1912). Wien. klin. Wschr., 25, 1187.

Samek, J. (1930). Arch. Derm. Syph. Wien, 159, 231.

Santalow, N. W., and Nowotelnowa, O. W. (1936). Ibid., 174, 259.

Scholtz, W. (1899). Ibid.; 49, 1.

Schridde, H. (1905). Z. Augenheilk., 14, 525.

Sidler-Huguenin, E. (1911). Arch. Augenheilk., 69, 346.

Smith, D. (1922). Lancet, 1, 1217.

Stühmer, A. (1921). Derm. Z., 32, 12.

Thomson, D., and others (1923). "Gonorrhœa." pp. 234, 460. London.

Touton, K. (1889). Arch. Derm. Syph. Wien, 21, 15. (1894). Berl. klin. Wschr., 31, 486; 515; 543.

Velhagen, C. (1937). Klin. Mb̆l. Augenheilk., 98, 20.

Waldstein, E. (1909). v. Graefes Arch. Ophthal., 72, 274.

Walker, K. M. (1913). Lancet, 1, 435.

Warthin, T. A. (1948). Amer. J. Med., 4, 827.

Wertheim, E. (1890). Wien. klin. Wschr., 3, 476. 